\title{
Interning and Investing: Rethinking Unpaid Work, Social Capital, and the "Human Capital Regime"
}

\author{
Sophie Hope* and Joanna Figiel** \\ *Birkbeck, University of London, London, UK, s.hope@bbl.ac.uk; **City University, London, \\ UK, joanna.figiel.1@city.ac.uk
}

\begin{abstract}
For young workers, interning is a strategy for speculating on one's asset portfolio. Students and graduates undertake internships as a way of maintaining their self-appreciation and avoiding depreciation in a "human capital regime." In this article, we explore the specific example of interning in the creative industries as the self-management of human capital vis-à-vis the human capital theses. Taking three cultural objects and recent representations of the issue of unpaid internships-Intern magazine, an advert for a "volunteering opportunity" student placement, and testimonies from interns-we analyze how unpaid work in the creative industries and the neoliberal version of human capital entrepreneurship can be seen as embodied by interns.
\end{abstract}

Keywords: internships, labour, unpaid work, social capital, human capital, self-management

Interning is one of the strategies employed by students and graduates to speculate on their asset portfolio. Students and graduates intern to maintain their self-appreciation and avoid depreciation in a "human capital regime." By human capital, we mean an individual's speculative relationship to their skills and knowledge. In this article, we explore interning in the creative industries as a specific example of the self-management of human capital. We take three recent cultural objects aimed at interns-a magazine, an advert, and a website-through which to analyze the labour relations of unpaid work in the creative industries, the forms of discrimination at play, and the weak ties and damaging capabilities that are a part of the practice of managing human capital. We re-imagine how the intern as an entrapped neoliberal subject investing in their portfolio career so as to affect and speculate on their human capital might disrupt the structural conditions of survival for the entrepreneurial self.

This article follows from our literature review of internship reports, guidelines, and toolkits published in the UK between 2009 and 2011 (Hope and Figiel 2012). ${ }^{1}$ In this report, we concluded, "The growing use of the word and application of internships perhaps continues to hide those more fundamental unresolved issues of elitism, inequality, bad-management, bullying and underfunding in the arts" (40). The literature we reviewed reflected a spectrum of positions, advice, and proposals, from suggestions of phasing out unpaid internships altogether, to "equalizing opportunities" for access to unpaid internships. Ten of the 23 documents we reviewed made recommendations that interns, if they fulfil worker status, should be paid National Minimum Wage while six did not. The HM Government's Unleashing Aspiration reports (2009 and 2010) emphasized the individual motivating himself or herself into employment, and that those with talent and potential will succeed. The unpaid internship, it seems, has become a necessary part of the doctrine of employability, an umbrella term used to describe the work of making oneself employable.

The language used in some of the literature we reviewed, including terms such as appreciation, aspiration, valorization, and entrepreneurship, embraces the capacity for someone to make the effort to maintain high levels of human capital. This is also the language of

${ }^{1}$ This report, Intern Culture, formed part of Artquest's research toward establishing a paid internship programme for 
internship adverts and interns themselves when describing their experiences. Many of the reports also recognized and problematized the necessary social and cultural capital needed to carry out an unpaid internship, such as one's family background and standing and network of connections. Reports such as Unleashing Aspiration were focused on generating equality of access to the professions rather than acknowledging the labour involved in establishing and maintaining cultural and social capital and the exclusions of individuals lacking the right kind of capital. Rather than address inequalities in terms of labour rights, employability appropriates the language of finance to describe education and interning as speculative investments.

The promotion of employability and the entrepreneurial self through university courses is now a key factor in how individuals and potential employers approach unpaid internships (Chertkovskaya et al. 2013). As declared on the website of the Higher Education Academy (HEA, the national body for enhancing learning and teaching in higher education), graduate employability is at the centre of the UK's Higher Education agenda. The HEA describe graduate employability as the "need to ensure that graduates are prepared for, and able to contribute to, the economy and society" (HEA 2015). In her 2003 article, "Neo-liberalism and the End of Educated Democracy," Wendy Brown questions the move away from a "broad and deep university education" towards job training: "What kind of world will be made through conceptions and practices of postsecondary education that reduce students to future human capital, citizens to manipulable consumers, and the public to GDP?" (Brown 2003, 22). This could be the kind of world in which the mis/over-use of the concepts of social and human capital is responsible for a state of generalized commodity fetishism where, as Ben Fine writes, "everything from our abilities to our states of mind becomes capital-like" (Fine 2010, ix).

The notion that education should above all service the economy was also highlighted in a recent speech by the Minister of State for Skills and Enterprise, Matthew Hancock MP: "One of the central goals of our reforms is to bring together employment and education. We are making education more rigorous and more responsive to employers" (Hancock 2014). The reports we examined in Intern Culture failed to address in any substantial way, however, the question of how this occurs. How does education service employers when so many graduates, especially in the creative industries, are self-employed? In our view, education, employability, and the internship are incubators for entrepreneurial selves where learning is put to work. It could be argued that interning appropriates and reproduces mechanisms of gendered unpaid reproductive and domestic labour, specifically, the invisible care and maintenance that interns perform both on themselves and for the organizations they work for. Rather than acknowledge these activities as exploitative forms of unpaid labour however, they are often presented as necessary (even desirable) for a functioning, productive, profitable society. The intern learns to become responsible for maintaining her own employability. In this article, we take some further steps towards understanding the intern as a subject who embraces the challenges of maintaining the entrepreneurial self.

The aim of this article is to reflect on the research on the proliferation of internships in the UK context, where intensifying processes of neoliberalization lead to an increased need and necessity for individuals to become entrepreneurs. While such processes affect employees across different sectors, they seem particularly visible and rife among those working for free in the hope of getting future employment in cultural and creative industries. The ill-defined interval of the internship that often exists between the expectations of learning and earning is integral to the protean career of entrepreneurial graduates (Bridgstock 2012). The internship is a period during which the graduate-symbolically, via their CV and/or physically and affectively via an embodied and passionate performance of commitment to the job-builds on and demonstrates their important connections and enthusiasm for work and offers their talent up to be tapped. In Vicki Smith's words, this participation is "performance, as people strive to demonstrate that they are employable; workers perform identity and emotion work in the service of this performance [...]" $(2010,291)$. This understanding of human capital as an enduring condition of speculative 
employment-being in a constant work-ready state-has led to all-pervasive relationships to work. As Smith points out, "definitions of work must be broadened to incorporate multiple types of labour," including, we argue, unpaid intern labour (294).

The three cultural objects we refer to in this article are Intern, a magazine launched in October 2013 by Alec Dudson, once an intern himself; ${ }^{2}$ a recent advertisement by the Institute for Contemporary Arts (ICA) in London seeking a student to fill a "volunteering opportunity" role; and Ragpickers Collection, an online archive of intern testimonies maintained by the UK-based collective Ragpickers. We chose these three examples to reflect different perspectives on the public presentation of interning, from the publicly-funded institution offering "opportunities" to the aspiring creative industry worker with a foot in the door to disillusioned individuals naming and shaming exploitative situations. Intern, a magazine put together by interns, for interns, has been created, we argue, to highlight the positive and rewarding aspects of unpaid internships, acting as an autoportrait of a certain section of this "workforce" in the UK. At the same time, the magazine reveals the kinds of activities interns undertake in order to get ahead in the creative and cultural industries. To complement and contrast this account, we include a recent student placement advert by the ICA that provides evidence of the continuing complicity of arts organizations perpetuating conditions of unpaid work. The placement advertised was meant for students, not necessarily as part of a credited work placement, but rather as a commitment "complimentary" to academic studies. ${ }^{3}$ Our third object is the collection of items on the website of Ragpickers collective, a London-based group raising awareness of internships and unpaid work in the arts. This material consists of evidence/personal accounts contributed by anonymous interns revealing aspects of their experiences at work. These accounts offer alternative narratives of interning that are often self-censored, and at worst silenced, in the quest for successful maintenance of one's social capital via an internship.

One of the goals of this paper is to bring a feminist reading of social and human capital to our understanding of interning as a contemporary neoliberal phenomenon. Departing from concepts of social and human capital defined by Pierre Bourdieu $(1984 ; 1986)$ and James Coleman (1988), we introduce a feminist challenge to the concept of human capital (and its vehicle, employability), which insists on analyzing the development and maintenance of networks of social relationships involved in gaining social capital as a series of gendered labour relations. These relations involve capitalizing on networks and personal relationships and friendships while the invisible social capital required to maintain these entrepreneurial bodies goes unnoticed, unpaid, and unrecognized as labour. We explore how developing these relationships as sets of capabilities can have positive and negative impacts on others around you and question the relevance or meaning of trust or strong ties that are supposedly important to gaining social capital. We then turn to Michel Feher's (2009) call to inhabit the neoliberal subject-our example being the intern-in order to think of possible ways to politicize the social relations involved in the unpaid work carried out by the intern.

\section{From Social Capital to Labour Relations: In Search of Spaghetti Cheesestrings}

Human capital is a contested term that has been tackled by, among others, Theodore Schulz (1961) and Gary Becker (1964) in the context of neo-classical economics; Bourdieu (1984; 1986), Coleman (1988), and Robert Putnam (2000) in relation to social capital; Foucault (2008/1978-9), Wendy Brown (2003; 2013), and Feher (2009) as part of the neoliberal, entrepreneurial economy; and Paula England and Nancy Folbre (1997), and Irene Bruegel

\footnotetext{
${ }^{2}$ Dudson states: "I did two internships: one at Domus and one at Boat Magazine. My internship at Boat was instrumental to what I'm doing now. I was able to make it work financially. I spent seven months sleeping on friends' couches. I went around by bike, didn't use public transport and worked a bar job for 30 hours a week. Which is fine but that's not a situation that everyone can magic up-it's not that simple" (cited in Segal Hamilton 2013).

${ }^{3}$ Arts universities in particular are trying actively to oppose such practices; see, for instance, Page 2014.
} 
(2005), who bring a feminist critique. Bourdieu divides capital into economic, cultural, and social forms. Economic capital refers to resources that can be converted into money and cultural capital-whether embodied, objectified or institutionalized-relates to a set of acquired knowledges, skills, and tastes (Bourdieu 1986). Social capital is the "sum of the resources, actual or virtual, that accrue to an individual or a group by virtue of possessing a durable network of more or less institutionalised relationships of mutual acquaintance and recognition" (Bourdieu and Wacquant 1992, 119). In this sense, we can view the internship as a process of or an extension of the investment in education to increase prospects in the long term.

Whereas Bourdieu refers to economic, cultural, and social capital, Coleman (1988) defines human capital as being "embodied in the skills and knowledge acquired by an individual [...] that make them able to act in new ways." Social capital exists in the relations between people (1001) and can impact on the creation of human capital. Indeed, human capital is dependent on the effectiveness of those social relations. Coleman explores the role social capital plays in different classes through a study of high school drop-outs in the US and their lack of access to social capital, such as parents' presence, number of children in the family, and a mother's expectations for her child to go to college. His understanding of social capital combines the "norms, rules and obligations" a person deals with together with their money-driven, self-interestedness (104-5). For example, social capital implies how a person's actions are influenced, shaped, and constrained by their environment but also understands people as being capable of independent action. For Coleman, social capital exists in the relation between people and is improved by the level of trust in that group (100-101). Smith, quoting Jone. L. Pearce, also highlights how "trustworthiness is a necessary-and underappreciated—condition of employability" (Smith 2010, 291). Coleman's understanding of human capital is based on an individual building up social capital in order to benefit from it in the long run in terms of money, pleasure, and/or satisfaction $(1988,116)$. In this article we understand the social capital of the intern to be the accumulation of a network of relationships. These connections might lead to an unpaid internship, which then promises to enhance an individual's network. The internship is considered a site for investing in human capital in the form of skills and knowledge, including training in how to acquire more social capital (through contacts, confidence, and charisma). Human and social capital are interconnected and co-dependent resources that the intern both requires and desires in a habitual dance of labour relations.

While concepts of social and human capital such as Coleman's might help explain the selfserving interests of an individual aiming to develop some semblance of a career, we look to a feminist reading of social capital to destabilize the norm of unpaid internship. A feminist rereading involves thinking about social relations beyond the cliques of family, community, and school and looking sideways to make connections and solidarities with others experiencing exploitative working conditions. Irene Breugel (2005), for example, referring to the dominance of social mobility discourse, writes "social capital sold itself as dealing with problems of deprivation and social cohesion, not inequalities of class, race or gender and therefore needs rethinking from a feminist perspective" (5). Working through these problems of deprivation reinforces and reproduces disadvantages of race, class, and gender, which are not accounted for in the theories of social capital to begin with, but instead are "brought back in" (Fine 2010, 60). In the case of the unpaid internship, we are less interested in equalizing access to opportunities to work for free than tackling the underlying inequalities that permeate and are perpetuated by the fragmentary forms of labour in which internships play a part.

As Emma Dowling $(2012,484)$ points out, not included in discussions of social capital but that must be addressed are the realities of labour: perspectives of labour need to be made visible in the "analysis of social capital." Dowling traces the recent trajectory of the concept of social capital in the service of austerity and "Big Society" discourses in the UK. In relation to these discourses, Dowling $(2012,485)$ calls for a politicization of social capital by drawing attention to 
the material realities of the double bind in which an individual finds herself in the current political and labour market climate, where neoliberal subjectivity is

on the one hand subsuming us completely into the production machine and relying on our cooperative and communicative connections to do so, while on the other pitting us against one another, turning us into competitive utility-maximising beings caught up in the affective anxieties of a rat race that is only being intensified by austerity.

How is free labour, such as the unpaid internship, harnessed at the same time as state disinvestment in "the reproduction of labour through the imposition of cuts and austerity"? (ibid. 484). The labour of reproducing working bodies (e.g., the domestic work of feeding, caring, and cleaning) remains invisible and unpaid, whilst qualities of social capital are being harnessed and reproduced in an effort to prove ourselves employable.

A good example for this discussion might be one of the items in the Ragpickers Collection: a packet of Spaghetti Cheestrings donated by an intern working at Blink Productions in Soho, London. This intern recalls spending "an entire day looking all around the area for a packet of Spaghetti Cheestrings" because one of the producers wanted to measure the length of a single Cheestring with a ruler for an advert they were making. The intern says this experience was "so utterly degrading and pointlessly stupid," expressing the "soul destroying" nature of the mission they were sent on, as was the content of the creative work being produced by the company they were interning for (Ragpickers 2013, Item \#4). For another intern, the job of interning "introduced [her] to real business" and she lists the seepage of unpaid work into her private life: "He [her supervisor] was telling me that I have to lose 15 kilos and my skirts are too short. He was cooking for me. He was washing my clothes. He was sleeping with me in one bed. Together we set up 3 shows during 2 weeks. Together we went for a couple of art fairs. Then I quitted [sic] and he deleted me on Facebook" (Ragpickers 2013, Item \#5). The chores illustrated in the Ragpickers Collection border on complex versions of modern day slavery. Although they wittingly entered into internships, these interns seem to be experiencing a kind of entrapment involving "affective anxieties" (Dowling 2012, 485). They acknowledge the absurdity of what they are doing but sign up for it anyway. While in the above cases the interns managed to escape, who knows for how long as their entrapment is embedded and embodied. Brown (2010) might call the experience of these interns "quotidian nihilism": "[neoliberalism] tells you what you should do: you should understand yourself as a spec of human capital, which needs to appreciate its own value by making proper choices and investing in proper things."

The Ragpickers Collection was set up as a space for expressions of exploitation and evidence gathering of labour relations in the context of interning. By exposing these problematic labour relations, the interns risk depreciating their own human capital by losing "friends" through making visible often-exploitative conditions. Despite the risk of burning bridges, the Low Pay Commission reported that in just over a year (from August 2012 to the end of September 2013), there had been 95 intern complaints to the Pay and Work Rights Helpline and arrears of pay for 171 workers totalling $£ 193,873$ had been identified in 12 cases (LPC 2014, 143). The Commission's report outlined a number of recommendations including a new legal definition of an internship; continued targeted enforcement; enforcement activity being publicised more widely; penalties for non-compliance being increased; and better advice being made available (144). While this is a welcome step towards recognizing the realities of labour involved in interning, it is of some concern that existing research we have engaged with often reveals little acknowledgement on the part of interviewed interns that there might be issues of inequality and exclusion in the intern culture they are a part of. David Lee $(2011,559)$, for example, states: "a number of my participants denied the importance of networks, and indeed denied it was an industry structured by anything less than sheer merit and talent." This could be because students, graduates, and novices are in the process of investing in their own self-appreciation 
and so it might be hard to step back and get some critical distance. Such conditions are challenged by the Ragpickers Collection, which goes some way to reverse the issue that interns themselves might be blind to problems of accepting unpaid work, particularly because, unlike the helpline, they make public the emotional and economic costs of maintaining one's human capital.

\section{Discrimination at the Gates: “We Don't Need to Tell Them, They Just Know From the Start"}

According to Lee's interviews with freelancers working in the British independent television production sector, jobs in the creative industries do not come through responding to adverts but via word of mouth through "loose acquaintances" or "weak ties" (2011, 553-4). Unlike Coleman's suggestion that trust between people increases their social capital, Lee points out that these career networks are distinguishable from "strong ties" built on trust. Instead, the kinds of networks relied on in the creative industries are weak, "based on thin, impersonal trust of acquaintances." Lee draws on the work of Mark Granovetter (1973) who found that job opportunities are often heard about via someone you do not have a strong connection to because they network with different social circles and have different kinds of information that might be useful to you. While this may be the case for individuals as they continue to work in the creative sector, of Lee's interviewees, all but one entered the industry through work experience that was "often gained through family networks" $(2011,556)$.

It is an open secret that nepotism is core to freelance careers in the creative industries but not everyone has the same privileges of access to friends or relatives with power or influence, or indeed the confidence to muscle in. The independent British public policy think tank The Social Market Foundation (2010) identified other entry barriers as being the requirement of a degree, poor career advice, and the unstable and precarious employment patterns in the creative industries making the career less viable for those without a financial safety net. Lee $(2011,549)$ focuses on networking as a mechanism of exclusion that "favours individuals with high levels of cultural and social capital" and thereby can be "a means of sustaining inequality, excluding social actors on the basis of class, race and social status" (552). He looks at the way people use their cultural capital to improve their social capital in order to climb the career ladder, focusing on the levels of confidence and the communication skills built up through "middle class socialization and life-styles" needed to access the networks on which a livelihood in the cultural sectors often depends (556).

Lee suggests networked freelancers need to present themselves as "flexible, enthusiastic and mobile." This language is echoed in the ICA volunteer placement advert, which requires "individuals able to think and react fast [...]" in their "very busy and lively office" (ICA 2014). An intern at Sprüth Magers Gallery contributed a set of emails to the Ragpickers Collection in which they were informed that their internship had been terminated after three days. The language used by the director is similar to that used by the ICA:

We are approaching our busiest time and we need to feel confident that everyone here is fully committed and willing to muck in and I am afraid this wasn't really the impression you have given. As a consequence, we think a continuation of the internship here is not the right thing for us, nor for you. (Ragpickers 2013, Item \#3)

The intern responds, pointing out her disappointment and the lengths she has gone to secure the internship, including the cost of organizing child care "in order to be as flexible as possible," and points out feeling voiceless in the process of her dismissal. In another email, the director explains that every other intern they have worked with "shows an innate sensitivity and respect towards their role" and have an "immediate awareness of what is and what is not appropriate in the gallery. We don't need to tell them, they just know it from the start" (ibid). This level of 
expectation of internalized and embodied modes of behaviour at work is also evident in the ICA advert, where students are required to "deliver exceptionally high standards of front-line customer service, support public access and engagement with contemporary art and quality of visitor experience" as well as "contribute to visitors' enjoyment, understanding and opportunities for learning through narrated interpretation, guiding and communication of stories and information about the ICA" (ICA 2014). The unpaid job being advertised already requires wellhoned communication and affective work skills and knowledge, meaning many students would not have access to this "opportunity" to preen their human capital.

In its report Work Placements in the Arts and Cultural Sector: Diversity, Equality and Access, the Equality Challenge Unit (2010) found that students, especially "disabled students, black and minority ethnic students, and those from disadvantaged socioeconomic backgrounds" experience difficulties trying to access or complete a work placement or an internship. Creative Skillset's 2012 census of the creative media industries found that representation of Black, Asian and minority ethnic people declined from 7.4 percent of the total workforce in 2006 to 6.7 percent in 2009 and just 5.4 percent in 2012 (Creative Skillset 2012, 4). "The proportion of the workforce described by their employers as disabled has remained the same since 2006, at 1.0 percent" (ibid., 5). This implies: "[...] those who don't make it are invisible to the successful. The excluded disappear" (Lee 2011, 561).

Tim Lindsay, CEO of the charity Design and Art Direction in London, writes in Intern magazine's first issue about why some might not take up an unpaid internship/work placement: "Anecdotally, women are less likely to be happy roughing it on a mate's floor. Agencies subsequently become dominated by a boisterous culture, and even less likely to attract female employees" (2013, 2-3). Lindsay goes on to note, "people from less well-off families may not know anyone to crash with... Seemingly unrelated problems such as cultural and gender diversity in the creative industries suddenly become a direct result of unpaid internships" (ibid., $3)$. He asks if the banning of unpaid intern adverts might "exacerbate the already endemic nepotism" (ibid., 8).

The lack of equal access to internships and, as a result, to creative professions could (and perhaps should) be understood as a form of discrimination. The Sprüth Magers intern found the director's actions to exhibit a "blind allegiance to concealed chauvinism" (Ragpickers 2013, Item \#3). We could add to this accusation by suggesting that the gallery director discriminates against those who do not know the codes of behaviour that are a prerequisite of the job. Interning in this case is about demonstrating and donating one's existing social and human capital to the organization rather than being a space for learning new skills from them.

\section{Weak Ties and Damaging Capabilities: Learning to Wait}

Paula England and Nancy Folbre (1997) present an expanded notion of human capital by replacing capital with capabilities. They define capabilities as a "state (involving a combination of motivation, skill and/or health) that requires some effort to develop, and that when developed, enables one to function in ways that contribute to the well-being of oneself or others" (2). The development of capabilities, they claim, is "beneficial for human well being at the collective level" (ibid.). Relating this concept to the case of the intern, rather than focus on individual self-gain (in terms of the intern's future earned income), we might consider the exercise of capabilities as benefiting, or indeed harming, people other than the intern. For example, we could think through the impact of interns on their co-workers, as highlighted by Sabina Siebert and Fiona Wilson (2013). Their study of unpaid work placements in media and creative environments shows the relationship of those undertaking unpaid work placements to their social capital is complicatedthe nature of social capital is multifaceted. Unpaid internships, they suggest, can have detrimental effects on labour relations and can constitute the erosion of trust between paid and unpaid workers (Siebert and Wilson 2013, 718). This contradicts Coleman's (1988) suggestion 
that social capital is built on trust: "The empirical evidence collected here suggests erosion of trust between unpaid workers motivated by a desire to enter the industry, freelance workers already in the sector and the employers, "Siebert and Wilson write (718).

Similarly, one Ragpickers Collection contributor reports on the strained relationship between them and the other staff in Sprüth Magers gallery where they were interning:

On a couple of occasions I have asked the gallery manager and other staff if there is any work for me to do but have been mostly told to sit and wait because everybody is "too busy with their work." I felt uncomfortable sitting next to the receptionist all the time because she acted very arrogant and self-important, making me feel like I am invading her sacred and adorned front of house kingdom. (Ragpickers 2013, Item \#3)

One of the basic capabilities that England and Folbre introduce is self-regulation: will power, attention, and restraint $(1997,4)$. The intern learns to sit and wait. The skill (or muscle memory) of self-regulation is learned over time by grabbing a series of perpetual "opportunities" in the hope that they will potentially translate into a career path. Self-regulation could be a prolonged period of adolescence, as pointed out by Ross Perlin (2011), but also a reflection of the type of work or person in an economic and political climate that relies on self-promotion. The interning phenomena is not just a temporary "strategy for waiting out economic downturn" (135) but a necessary term of (un-) employment and extended work experience that is considered part of the creation of the sole trader. The preference or desire to intern and the skill of self-regulation it requires (such as foregoing other activities and pay), have been internalized. As England and Folbre $(1997,5)$ state: those people "can be relied upon more to exercise the skill even under loose or no surveillance."

Smith (2010) explores three ways that people try and enhance their employability: identity work, training and networking, and labouring in unpaid and marginal paid positions. She writes: "The unemployed and underemployed spend hours, often full-time, learning the self-presentation and interactional ropes of flexible workplaces, reconstructing themselves, and searching for jobs" (285). She goes on to suggest that "volunteering also provides the opportunity for volunteers to audition: to demonstrate their work ethic, their trustworthiness, and their fit with an organization" (291). The internship is a place for practicing social skills and presentation of the self. In an article in Intern, for example, Ben from design collective OWT, stresses how "people skills are imperative for a successful internship" (Bennett 2013, 2). The blurring of work and nonwork identities is echoed in the words of Sarah of OWT who suggests that if interns "go for a pint with them, that's a promising relationship [...] As an intern you have to show you want to work with these people, not simply because of the company they work for, but because of who they are" (ibid., 2-3). Networking becomes something you should be doing: "it takes on a hegemonic and normative force" (Lee 2011, 562). Entrepreneurial tendencies are embodied in the intern for whom, as OWT point out, contacts have become a form of currency (Bennett 2013).

Irena Grugulis and Dimitrinka Stoyanova's research on a television production company acknowledges the way people learn through socialization and gain experience by observing and working with others (2011). They point to the problematic assumption, however, that workplaces are "coherent communities, containers of competence where the skilful are available for novices to consult and observe" (343). Their research questions how much can be learnt through social interaction (and the trust that is needed for social capital to grow, according to Coleman), when the workforce is notoriously fragmented and freelance. How and where do those networks of trust develop? 'Outsourcing 'at will' contracts and freelance work are much less effective at supporting communities of practice than stable work groups or vertically integrated bureaucracies" (Grugulis and Stoyanova 2011, 343). Their term the missing middle refers to the community of trainees who have contact with other "novices" and occasionally "company ownermanagers," but not to the experienced professionals who could aid their learning. In the 
research they carried out (2005-2006 fieldwork at an independent production company), the novices had little contact with the professional freelancers, who were geographically separate and only around for short-term contracts. There was "no continuity of relationships" or chance to do tasks that would challenge them (344). The novices were left to support and train each other, an experience of "the blind leading the blind," according to one novice. This is a result, Grugulis and Stoyanova suggest, of labour market structure (fragmented, overworked, based on shortterm contracts): "...without ready access to visible, transparent expertise novices struggle to learn, or even know what they need to learn" (349). They end on a depressing note: "it is not clear how the industry's current cohort of novices will ever acquire the skills taken for granted by previous generations of workers" (350). The pursuit of capabilities has negative and positive effects on the intern and those around them. Further, such capabilities can also be questionable in themselves. For example, the ability to wait and not ask questions, develop superficial relationships and false friendships. For whom are these capabilities desirable and who do they benefit?

\section{Intern as Neoliberal Subject, or "The Constant Need to Organize Myself to the Minute"}

Feher $(2009,24)$ describes human capital as a "dominant subjective form," a "defining feature of neo-liberalism." Human capital, he argues, is to be embraced, in order to be transformed: "Instead of denouncing and lamenting the personalization of politics as the strategy through which neoliberalism causes people to lose sight of their collective interests, playing the human capital card could thus be a way of relaunching the politicization of the personal" (25).

Feher makes a link between the shift towards globalized, unregulated markets and the neoliberal version of human capital. Whereas old forms of capitalism were based on investing for future commercial profits over a period of time, the focus now is on maximizing "distribution of dividends in the short term," "capital growth or appreciation," and "stock value" (27). Let us try and map this financial language onto the case of an "unpaid voluntary placement" advertised at the ICA. Theodore Schultz (1961) and Becker (1964) might have understood the intern as being motivated to work unpaid in the hope that there will be delayed returns on that investment in terms of future earnings, material rewards, or "psychic" benefits. Taking Feher's view on human capital, the intern as a neoliberal subject is investing in his or her own stock value. The placement at the ICA reflects a system that relies on students undervaluing their stock value so that they willingly and competitively take up the "opportunity" of an unpaid placement to increase their value in the future. In economic terms, appreciation means an increase in value of an asset. Significantly, value does not increase because of improvements or additions to the asset but because of other economic factors such as scarcity or inflation. In the case of the intern, there is a pressure to increase their own value-for example by improving their skills, networks, confidence etc.-but their levels of appreciation are also dictated by the fluctuating, "turbulent," unpredictable labour markets around them. The intern can invest all they can in their human capital, but their appreciation or depreciation might be dependent on factors beyond their control. Feher suggests that the neoliberal subject cannot own her human capital. Unlike the "free labourer" who sells their labour power to the capitalist in return for a wage, the neoliberal subject-in our example, the intern-can only ever have a speculative relationship to their human capital. The intern can modify, upgrade, and improve but not sell their human capital (34).

This speculative relationship to human capital is evident in the pages of Intern magazine. For the interns presenting their stories, it is as if work wraps around them like a second skin and becomes an integral part of their identity. "Each feature that tackles the [internship] debate headon offers a subjective take on things and while this structure may frustrate some, internships are by their very nature, personal experiences" (Dudson 2014, 5), the editorial foreword warns, and 
delivers on its promise. Most case studies in the magazine are both personal and highly individualized accounts. While contributors to the magazine are paid, an overwhelming majority of features and internship reports talk about placements and internships that were unpaid. For example, one interviewee who has already made her name in the business, Jessica Walsh, says on interns: "Ours are unpaid. We pay for their lunches. I think it's on a situational basis whether people are comfortable with that, and can handle that." Her own internship, eventually leading to partnership at Sagmeister and Walsh, was presumably also unpaid (Quito 2014, 26). The narratives here give various accounts of the self-investment process, for example:

I understand just how valuable free [labour] can be. I spend around about $60 \%$ of my working life in non-fee paying work. I work for free/ [goes on to describe various activities] Everything I do for free I do because there will be, somewhere not too far down the line, a payback. [...] It is a selfish act [...] to keep myself working on terms that suit my lifestyle. (Germains 2014, 21)

A contributor to issue 1, Daniel Cooper, devised a project where he travelled around the world working for free for two days at a time for design companies, in exchange for one day of their time in return. This proposition was well received, he writes, because "it wasn't much of an investment on their part" (Cooper 2013, 6). The kind of things the design companies gave Cooper in return included showing him around their city, a bike trip, breakfast, and access to nightlife. One could argue that these were mutually beneficial leisure pursuits rather than the company working for free for Cooper for a day. During his project to test out the nomadic, transient lifestyle of the creative workforce, he found "the constant need to organise [him]self to the minute" extremely tiring (ibid.).

According to the investment model of human capital, the nomadic design intern swapping two days of unpaid work for one day of the company's time, or the person spending 60 percent of their work time unpaid would supply a credit slip to the place they are doing the internships to be cashed in at a later date. In neoliberal reality, however, these undelivered symbolic credit slips accumulate in the shape of what Feher (2009) refers to as self-appreciation (they remain speculative). As Perlin $(2011,132)$ reminds us, investing in education, training, and the "internship bonus" with the hope of future higher wages is a risk, especially in a sector that does not have many paid permanent posts: "For many, the return on investment doesn't come, the economic landscape changes in the meantime, or an incomplete investment spells disaster."

Self-esteem is the key to maximizing human capital, and "life may be thought of as a strategy aimed at self-appreciation" (Feher 2009, 28). Distinguishing the subject form of human capital from the pre-neoliberal subject of the free labourer (who relies on the separation between the alienated worker-self and the self that resists commodification), neoliberalism "treats people not as consumers but as producers, as entrepreneurs of themselves or, more precisely, as investors in themselves, as human capital that wishes to appreciate and to value itself and thus allocate its skills accordingly" (30-31). The intern is concerned with the "impact of their conducts" as this may have an effect on the "level of their self-appreciation or self-esteem" (27). As investees in their own career destinies, they are responsible for managing their own value, frantically trying to avoid any depreciation in value. "Neo-liberal subjects," Feher writes, "do not exactly own their human capital; they invest in it. In fact, anything they do, no matter how ill advised or mundane, is an investment in their human capital" (26). This often means an additional portion of unpaid work performing enthusiasm for a speculative career. This demonstration of commitment and enthusiasm that takes place in the space of the internship becomes the self-management of self-appreciation. As well as being motivated by the hope of future pay-off, it is part and parcel of investing in the entrepreneurial self.

As a magazine focused on the creative industries, the articles in Intern embrace selfpromotion and the importance of "making a name for yourself." Articles reflect the characteristics of cultural and social capital needed to enter the profession. These "capabilities" (a mix of 
enthusiasm, confidence and access to networks) are learnt and built up through "middle class socialisation and life-styles" (Lee 2011, 556). There is a sense that the more you believe in yourself and the work you do, the more successful you will become. The magazine is a demonstration of this self-appreciation. In one article, OWT state: "not being paid doesn't matter if you're gaining a lot of information and contacts" (Bennett 2013, 9). Such statements seem typical of those who have internalized the relentless neoliberal calls to perpetual selfimprovement that surrounds the subject of working for no pay, language that is echoed in the advertisements, career fairs, workfare and university prospectuses at the same time. Phoebe Moore (2009) suggests employability "requires people to use every waking minute for preparation for entering into an unpredictable job market, or for management or education of the self ... in work, meaning that everyday life is subordinated to these preparations and activities" (245). While, according to Feher, "individuals must have access to training programs during periods of unemployment to increase their employability and thus ward off the depreciation of their human capital" $(2009,39)$. This relates in equal measures to interns who do not take on government provided or otherwise required training programmes, but multiple unpaid internships and work placements in the attempt to achieve employability and subsequently, gainful employment. These are often facilitated and encouraged by universities and, as we have shown in the Intern Culture report, encouraged by the policy surrounding the issue.

\section{Conclusions: From Organizing Myself to Organizing With Others}

In this article, we have reflected on three approaches to the internship: Intern magazine, an advert for an unpaid placement at the ICA, and a collection of items from interns on the Ragpickers website. All three examples illustrate the ways, both in terms of ideology and in terms of the qualities of interning, that the individual is expected to (im)prove their employability through, for example, the ability to follow orders without question (the Cheestring mission), to learn the discipline of waiting patiently (the silenced Sprüth Magers intern), to enthusiastically network (a strategic drinking session), and to perform high levels of customer service (on the ICA front-line). The audiences of the advert, magazine, and website might overlap-they are all aimed at interns - and they share the language of investment and opportunity. While the advert and Intern magazine tend to reproduce this language, the Ragpickers Collection attempts to undo some of the assumptions by exposing the realities of labour that interning entails. The Collection is an example of interns looking critically at the conditions they are in and building awareness of the impact their labour relations and armoury of capabilities are having on themselves and those around them.

While individual cases outlined in Intern and the Ragpickers Collection are important in understanding the terrain of exploitation, there is a need to move beyond singular cases. We have attempted to join up these examples so as to consider the underlying systemic inequalities that have allowed internships to become the norm. Re-imagining the intern as an entrapped neoliberal subject investing in their portfolio career might disrupt the structural and implicit conditions of survival for the entrepreneurial self. This involves acknowledging and drawing attention to the labour of unpaid work and its all-pervasiveness, problematizing the powerrelations and exploitative characteristics of capability-building (who is left in the wake of an individual's human capital expansion?), and recognizing the possible solidarities that could result from this. It would also bring the realities of inequalities to the fore. In such a guise, interning would be a subjectivizing experience, but also a collectivizing one, where working conditions are challenged not just to improve an (already privileged) individual's experience, but to recognize broader exclusions and exploitations necessary for the space of the internship to exist in the first place.

From the perspective of employability, by subverting the "proper choices," as neoliberal subjects we could begin to question, as Feher does, "what constitutes an appreciable life"? 
$(2009,41)$. He suggests that it is through the personalization of the political that steers people away from their collective interests. He asks if it is possible to play the human capital card strategically, in an attempt to achieve the reverse-the politicization of the personal-although does not elaborate on how that could be possible. Through our mapping of the context of internships and the examples of human capital at work, we are thinking towards a politicization of the intern.

Internships could be seen as a force for perpetuating inequalities, exploitation, and discrimination by developing a closed social system of self-serving capabilities that interns alone can excel in but that necessarily excludes others - the "disappeared majority," as Lee (2011) notes, that needs to be "brought back in," as discussed by Fine (2010). Rather than demonize the intern, however, could we embrace this figure and instead explore how networks of solidarity among co-workers stretch beyond the individual's self-interest towards an alternative coappreciation that can disrupt and crack open the closed networks that perpetuate inequality in the sector? Rather than the social networks being built for personal gain, for example, can they be reconsidered as social networks of solidarity that acknowledge systemic inequalities and difference? At present, there seems to be a race towards improving the quality of exploitation for all.

While there is increasing awareness of these issues in academic discourses, public policy, higher education teaching the creative industries themselves, the discrimination inherent in the internship system continues as the loopholes multiply to protect vested interests, including those of the entrepreneurial self. From our readings of the texts for this article, we have learnt that human capital can be seen as affecting not just future earnings: it is also becoming a prerequisite of one's life-work. If we recognize the collective aspect of human capability development, however, might we be able to do something different with it? How can the creative capabilities inherent in the intern be understood, developed, and exercised in a form of solidarity that benefits others?

\section{References}

Becker, Gary. 1964. Human Capital: A Theoretical and Empirical Analysis with Special Reference to Education. Princeton: Princeton University Press.

Bennett, Andy. 2013. You Get OWT What You Put In. Intern 1: 1-9.

Bourdieu, Pierre. 1984. Distinction: A Social Critique of the Judgement of Taste. London: Routledge.

Bourdieu, Pierre. 1986. The Forms of Capital, In Handbook for Theory and Research for the Sociology of Education, edited by J. Richardson, 241-258. New York: Greenwood Press.

Bourdieu, Pierre and Loic Wacquant. 1992. An Invitation to Reflexive Sociology. Chicago, IL.: University of Chicago.

Bridgstock, Ruth. 2012. Not a Dirty Word: Arts Entrepreneurship and Higher Education. Arts and Humanities in Higher Education 12 (2-3): 122-137.

Brown, Wendy. 2003. Neo-liberalism and the End of Liberal Democracy. Theory \& Event 7 (1). Accessed June 15, 2014. http://lchc.ucsd.edu/cogn_150/Readings/brown.pdf.

Brown, Wendy. 2010. Wendy Brown Interview. Accessed June 15, 2014. http://marxlacanzizek.wordpress.com/2010/02/28/wendy-brown-interview/.

Brown, Wendy. 2013. Neoliberalism, De-Democratization, Sacrifice. La Clé des Langues. Lyon: ENS LYON/DGESCO. Accessed June 13 2014. http://cle.ens-lyon.fr/anglais/neoliberalism-dedemocratization-sacrifice-181089.kjsp?RH=CDL INF010000\#page.

Breugel, Irene. 2005. Social Capital and Feminist Critique. In Women and Social Capital, edited by Jane Franklin, 4-17. London: London South Bank University. Accessed June 132014. http://www.Isbu.ac.uk/ data/assets/pdf file/0007/9439/women-social-capital-families-researchworking-paper.pdf.

Coleman, James. 1988. Social Capital in the Creation of Human Capital. American Journal of Sociology, Vol. 94: 95-120.

Cooper, Daniel. 2013. Reflections of a Nomadic Designer. Intern 1: 1-8 
Creative Skillset. 2012. Annual Report 2011-2012. Accessed June 22, 2014. http://creativeskillset.org/about us/publications.

Dowling, Emma. 2012. Tales of "Much of a Muchness": Adventures in the Land of Social Capital. Ephemera: Theory and Politics in Organization, 12 (4): 480-485.

Dudson, Alec. 2014. Editor's Letter. Intern 2: 5.

Equality Challenge Unit. 2010. Work Placements in the Arts and Cultural sector: Diversity, Equality and Access. Accessed June 15, 2014. http://www.ecu.ac.uk/publications/files/work-placements-in-the-artsand-cultural-sector.pdf/view.

England, Paula and Nancy Folbre. 1997. Reconceptualizing Human Capital. Presented at the annual meetings of the American Sociological Association, Toronto, Canada, August 1997. Accessed June 12 2014. http://apps.olin.wustl.edu/macarthur/working\%20papers/wp-englandfolbre2.html.

Feher, Michel. 2009. Self-Appreciation; or, The Aspirations of Human Capital. Public Culture 21 (1): 2141.

Fine, Ben. 2010. Theories of Social Capital: Researchers Behaving Badly. London: Pluto.

Foucault, Michel. 2008/1978-9. The Birth of Biopolitics: Lectures at the Collège de France 1978-1979. New York: Palgrave Macmillan.

Germains, Gemma. 2014. The Lost Generation. Intern 2: 17-21.

Granovetter, Mark. 1973. The Strength of Weak Ties. American Journal of Sociology 78 (6): 1360-1380

Grugulis, Irena and Dimitrinka Stoyanova. 2011. The Missing Middle: Communities of Practice in a Freelance Labour Market. Work, Employment \& Society 25: 342-351.

Hancock, Matthew. 2014. Speech. Accessed June 15, 2014. https://www.gov.uk/government/speeches/strengthening-links-between-education-andemployment.

HEA. 2015. Employability. Accessed April 2015. https://www.heacademy.ac.uk/workstreamsresearch/themes/employability.

Hope, Sophie and Joanna Figiel. 2012. Intern Culture. Accessed June 15, 2014. http://www.artquest.org.uk/uploads/recovered files/Intern\%20Culture\%20report.pdf.

ICA. 2014. ICA Student Placement: Creative Department - Exhibitions. Voluntary Role Description. London: ICA.

Lee, David. 2011. Networks, Cultural Capital and Creative Labour in the British Independent Television Industry. Media, Culture \& Society 33 (4): 549-565

Lindsay, Tim. 2013. Ideas Need People. Intern 1: 1-10.

Low Pay Commission. 2014. National Minimum Wage Report. Accessed April 2015. https://www.gov.uk/government/uploads/system/uploads/attachment_data/file/288847/The_National_M inimum Wage LPC Report 2014.pdf.

Moore, Phoebe. 2009. UK Education, Employability, and Everyday Life. Journal for Critical Education Policy Studies 7 (1): 243-274.

Page, Libby. 2014. Arts Universities Oppose Unpaid Internships. The Guardian, January 9. Accessed September 12, 2015. http://www.theguardian.com/education/2014/jan/09/arts-universities-againstunpaid-internships.

Perlin, Ross. 2011. Intern Nation: How to Earn Nothing and Learn Little in the Brave New Economy. London \& New York: Verso.

Pearce, Jone.L. 2000. Employability as Trustworthiness. In Relational Wealth: The Advantages of Stability in a Changing Economy, edited by C. R. Leana and D. M. Rousseau, 79-90. New York: Oxford University Press.

Putnam, Robert. 2000. Bowling Alone: The Collapse and Revival of American Community. New York: Simon Schuster.

Quito, Anne. 2014. Casting Jessica Walsh. Intern 2: 22-28.

Ragpickers. 2013. Ragpickers Collection. Accessed November 20, 2014. http://ragpickers.tumblr.com/collection.

Schultz, Theodore. 1961. Investment in Human Beings. Chicago: Chicago University Press.

Segal Hamilton, Rachel. 2013. Alec Dudson: Intern Magazine. Ideas Tap, September 16. Accessed September 12, 2015. http://www.ideastap.com/ldeasMag/the-knowledge/alec-dudson-intern-magazineinterview. 
Siebert, Sabina and Fiona Wilson. 2013. All Work and No Pay: Consequences of Unpaid Work in the Creative Industries. Work Employment Society 27: 711-721.

Smith, Vicki. 2010. Enhancing Employability: Human, Cultural, and Social Capital in an Era of Turbulent Unpredictability. Human Relations 63: 279-300.

Social Market Foundation (SMF). 2010. Disconnected: Social Mobility and the Creative Industries. London: SMF.

\section{About the Authors}

Sophie Hope

Sophie Hope is a practice-based researcher in the Film, Media and Cultural Studies Department at Birkbeck, University of London. She has worked as an independent curator and evaluator of public and socially engaged art and developed a number of practical projects through which to research cultural policy, labour conditions and community art histories. Her PhD (completed in 2011), entitled "Participating in the Wrong Way? Practice Based Research into Cultural Democracy and the Commissioning of Art to Effect Change," explored the limits and possibilities of criticality in the context of an artists' contract.

\section{Joanna Figiel}

Joanna Figiel is a doctoral candidate at the Centre for Culture Policy Management, City University London. Her research focuses on labour issues, unpaid work, precarity and policy within the creative and cultural sectors. She is a member of the ephemera editorial collective and collaborates, among others, with Minor Compositions, Artleaks, and the Free/Slow University of Warsaw. 